\title{
A construção do SUS e o planejamento da força de trabalho em saúde no Brasil: breve trajetória histórica
}

\author{
Construction of the Unified Health System and health workforce planning in Brazil: a brief \\ historical trajectory
}

Manoela de Carvalho', Nelson Rodrigues dos Santos², Gastão Wagner de Sousa Campos

\footnotetext{
Doutora em Saúde Coletiva pela Universidade Estadual de Campinas (UNICAMP) - Campinas (SP), Brasil. Professora do curso de enfermagem da Universidade Estadual do Oeste do Paraná (Unioeste) - Cascavel (PR), Brasil. manoelacarv@gmail.com

${ }^{2}$ Doutor em Medicina Preventiva pela Universidade de São Paulo (USP) - São Paulo (SP), Brasil. Presidente do Instituto de Direito Sanitário Aplicado (IDISA) Campinas (SP), Brasil. nelson@idisa.org.br

${ }^{3}$ Doutor em Saúde Coletiva pela Universidade Estadual de Campinas (UNICAMP) - Campinas (SP), Brasil. Professor Titular do DMPS/FCM da UNICAMP - Campinas (SP), Brasil. gastaowagner@mpc.com.br
}

RESUMO: A necessidade de planejar o número, o perfil e a distribuição da força de trabaIho do setor saúde tem sido uma das grandes preocupações dos gestores, trabalhadores e usuários envolvidos na reforma sanitária brasileira, desde a concepção do Sistema Único de Saúde. Este estudo bibliográfico e documental apresenta uma análise da trajetória histórica das políticas de planejamento da força de trabalho em saúde no Brasil, destacando a recrudescência de problemas identificados desde a década de 1970 nessa área, em grande medida, pela manutenção de um modelo assistencial que privilegia os interesses privados em detrimento das necessidades e dos direitos da população.

PALAVRAS CHAVE: Recursos humanos em saúde; Políticas, planejamento e administração em saúde; Sistema Único de Saúde.

\begin{abstract}
The need to plan the number, profile and distribution of health workforce has been a major concern of managers, workers and users involved in the Brazilian health reform, since the National Health System was first designed. This bibliographic and documental research presents an analysis of the historical trajectory of health workforce planning policies in Brazil, highlighting the resurgence of problems identified since the 1970s in this area, largely for the maintenance of a care model that favors the private interests at the expense of the population's rights and needs.
\end{abstract}

KEYWORDS: Health manpower; Health policy, planning and management; Unified Health System. 


\section{INTRODUÇÃO}

Este texto apresenta aspectos da trajetória histórica das políticas de planejamento da força de trabalho em saúde (PFTS), desde a proposição e a institucionalização do Sistema Único de Saúde (SUS) até a recente inserção do tema no campo da gestão do trabalho em saúde. Pressupooe-se que as experiências atuais de PFTS estejam vinculadas ao contexto mais amplo de construção do SUS e aos contextos social e político do período dos anos de 1970 até os dias atuais.

Enfatiza-se, assim, a recorrência de problemas relacionados à força de trabalho da saúde (FTS), desde o início do período analisado: especialmente os desequilíbrios na distribuição geográfica dos profissionais, com concentração em centros urbanos; a centralidade no profissional médico e no desenvolvimento limitado das outras categorias profissionais; e a tendência à formação médica especializada, centrada no hospital e em tecnologias sofisticadas e desvinculadas das necessidades do sistema de saúde.

Apresentam-se, também, os principais enfoques metodológicos propostos, em sua maioria, pelos países desenvolvidos, para o planejamento da FTS por meio de agências internacionais, em especial, a Organização Pan-Americana de Saúde (OPAS). Em seguida, analisam-se os impactos para viabilizar as mudanças necessárias para a consolidação do SUS, com seus princípios de universalização, integralidade e igualdade no acesso aos serviços de saúde.

Trata-se de uma revisão bibliográfica e documental, para a qual utilizaram-se textos e artigos disponíveis em bases de dados virtuais de acesso aberto sobre aspectos relacionados à política social e de saúde internacionais - notadamente, os da América Latina e documentos que influenciaram o desenvolvimento de políticas de saúde e dos processos de planejamento da FTS no Brasil. Muito do pensamento brasileiro e deste campo de práticas sociais e de políticas públicas, construídas nas últimas décadas, esteve assentado nos estudos, recomendaçóes e eventos realizados pela OPAS (PIRES-ALVES; PAIVA, 2006); portanto, documentos e textos que abordam a história da cooperação técnica entre a OPAS e o Brasil também se constituíram em fontes de informação.

Alguns países já vinham experimentando o processo de planejamento de recursos humanos para a saúde desde meados da década de 1950, como foi o caso da antiga União das Repúblicas Socialistas Soviéticas (URSS) e de outros países socialistas daquele momento. Entretanto, apesar de a Organização Mundial de Saúde (OMS) ter promovido a discussão, entre seus países membros, sobre temas relacionados aos recursos humanos em saúde, desde 1948, ofertando dados estatísticos e indicadores de saúde (como mortalidade, morbidade, formação de pessoal e normas para planejamento), na América Latina, essas experiências só tomaram consistência e ganharam popularidade a partir dos anos 1970, com a participação da OPAS (HALL; MEJÍA, 1978).

De acordo com Quintana; Rígoli; Padilha (2002), o planejamento de recursos humanos foi uma atividade importante para a maioria dos Ministérios de Saúde dos países americanos e uma linha de cooperação também importante para a OPAS/OMS, desde os anos 1960 até início dos anos 1980. O debate se polarizava entre as propostas de planejamento normativo e estratégico. Porém, essa prioridade de planejamento para as organizaçôes perdeu força até quase desaparecer, e, apesar da ausência de planejamento de recursos humanos na década de 1990, observa-se, atualmente, na América Latina, uma tentativa de mudança, na medida em que problemas relacionados aos recursos humanos têm exigido mais atenção nas agendas políticas.

A permanência de muitos dos problemas identificados há quatro décadas pode indicar, portanto, a complexidade que caracteriza o campo do planejamento da FTS.

\section{A década de 1970: planejamento au- toritário com enfoque normativo em um Estado administrador-interventor}

Apesar de os debates terem-se iniciado nos anos 1950, nenhum país, até a década de 1970, havia colocado em prática os planos ou estudos realizados sobre a FTS, o que levou os ministros de saúde a recomendar 
a integração do planejamento de recursos humanos ao planejamento geral de saúde, no Plano Decenal de Saúde para as Américas, em 1972 (OPAS, 1974).

Entre as décadas de 1960 e 1980, os serviços reduziam-se à contribuiçấo da categoria médica e a uma maior disponibilidade desses profissionais, o que implicava a necessidade de conhecer sua disponibilidade e as necessidades futuras para alcançar metas padronizadas internacionalmente, além do ritmo de formação pelas escolas médicas. Confiava-se nas possibilidades de um plano tecnicamente fundamentado, mesmo se desconsiderando a realidade política, que, frequentemente, negava muitos dos pressupostos do Plano; apesar de previstas no modelo, as variáveis econômicas eram ignoradas na prática (QUINTANA; RÍGOLI; PADILHA, 2002).

Alguns eventos internacionais foram importantes para a disseminação e a sistematização de experiências de planejamento de recursos humanos entre os países americanos. Em 1973, realizou-se, em Ottawa (Canadá), a Conferência Panamericana sobre Planejamento de Recursos Humanos em Saúde (RHS), em que se identificaram problemas, como: a centralidade no profissional médico e o desenvolvimento limitado das outras categorias profissionais; a concentração de pessoal em centros urbanos; e a tendência à formação especializada, centrada no hospital e em tecnologias sofisticadas, porém, desvinculada dos problemas dos serviços de saúde. A expressão propagada na referida Conferência resumia a inquietação dos participantes: "É necessário formar os recursos humanos que os países necessitam" (OPAS, 1974, s.p.).

As recomendaçóes dessa Conferência destacaram a necessidade de os programas nacionais de planejamento de RHS estarem integrados aos planos nacionais de saúde, e de que desencadeassem esforços para elaborar planos de longo prazo. Enfatizaram, ainda, que, nos países cujo sistema de saúde estivesse subdividido em setor público e privado, o setor público liderasse a tomada de decisóes, inclusive no campo de recursos humanos. Também indicaram as necessidades de: articulação dos setores de educação e saúde, com a participação da comunidade; organização e aperfeiçoamento de sistemas de informação sobre RHS e necessidades de saúde e de atenção não cobertas; e transferência de conhecimentos e responsabilidades dos profissionais de saúde à comunidade, para ampliar a cobertura dos serviços de saúde, particularmente, os das áreas rurais (OPAS, 1974).

Além dos eventos, vários outros documentos foram publicados pela OMS e pela OPAS visando a instrumentalizar os países-membros para planejar os RHS. Atendendo à recomendação da 29a Assembleia Mundial de Saúde (1976), a OMS publicou documento intitulado Planificación del Personal de Salud: principios, métodos, problemas, em 1978, no qual considerava que o planejamento de pessoal de saúde evitaria a subutilização do sistema hospitalar, por fatores como: a falta de profissionais; a migração de profissionais de saúde de um país a outro, em busca de melhores empregos; a falta de empregos para profissionais de saúde, cujos cursos de graduação haviam sido criados sem perspectiva de absorção pelo sistema de saúde; os desequilíbrios na distribuição de profissionais entre as diversas regiōes; a carência absoluta de profissionais e, por consequência, de serviços de saúde em determinadas localidades, contra o excesso em outras (HALL; MEJÍA, 1978).

A OMS admitia ser possível eliminar os conflitos de interesses a partir de uma 'firme decisão', já que a saúde seria um dos poucos setores em que todos estariam do mesmo lado: contra a doença. Portanto, muitos problemas foram vinculados ou à ausência de um planejamento bem elaborado ou à má execução dos planos. Acreditava-se, assim, no planejamento como base racional para a tomada de decisóes, cujo processo compreenderia, basicamente, a identificação e a análise dos problemas; a determinação das possíveis opçóes; a seleção da solução adequada; a determinação dos métodos técnicos que seriam utilizados; e a definição dos objetivos do programa e das atividades a serem realizadas (HALL; MEJÍA, 1978).

Atualmente, entretanto, várias análises indicam que a complexidade do campo dos recursos humanos deve ser considerada no processo de planejamento, observando não apenas a dimensão da educação, que conforma a oferta de profissionais, mas, também, a dimensão do trabalho, que estabelece a demanda; e que parte dessa complexidade deve-se à própria participação dos diversos sujeitos envolvidos, como sindicatos, corporaçóes profissionais, instituiçóes de ensino e organizaçóes 
de saúde, além de questóes que extrapolam o setor saúde, como as econômicas e políticas (QUINTANA; RÍGOLI; PADILHA, 2002).

Já quanto à questâo metodológica do planejamento de RHS, os limites estavam dados pela ideia de que o futuro era passível de previsóes por meio da extrapolação dos recursos do presente; de que a confiança nos critérios de qualidade técnica do plano eram condiçôes necessárias e suficientes para torná-lo factível; pelo caráter isolado dos demais setores da gestão dos serviços de saúde, gestão essa, geralmente, realizada depois de finalizado o planejamento dos serviços; e pela utilização acrítica de indicadores padronizados internacionalmente (QUINTANA; RÍGOLI; PADILHA, 2002).

A OMS recomendava que o processo de planejamento de RHS estivesse fundamentado em dados estatísticos, e contava, inclusive, com a ajuda de estatísticos para a coleta e análise desses dados. Porém, naquele período, muitos países não dispunham de um banco de dados adequado para prover o processo de planejamento. O diagnóstico proposto considerava apenas aspectos quantitativos, relacionados à realidade analisada, na tentativa de transformá-los em parâmetros a partir de um modelo preexistente (SPINELLI; TESTA, 2005).

Além disso, pelo enfoque normativo, o planejamento da FTS está subordinado aos demais campos da política, do planejamento ou da saúde, e tanto concebe os trabalhadores como insumos quanto os recursos tecnológicos ou financeiros e as universidades como 'fábricas de mão de obra qualificada'. Ao invés de considerar a realidade como ela é, com seus conflitos e jogos de interesses, essa corrente do planejamento indica como a realidade "deveria ser", numa tentativa de normatizá-la (ROVERE, 2006).

É desta década o conceito de planejamento de RHS, definido como:

O processo pelo qual se determinam o número de pessoas e o tipo de conhecimentos, habilidades e atitudes necessários para o alcance das metas de saúde projetadas e, em última instância, os objetivos de saúde. Este planejamento implica, também, a determinação de quem fará o $q u \hat{e}, q u a n d o$, onde, como, com quais recursos e para quais grupos da populaçáo de modo que se disponha de pessoal com os conhecimentos $e$ competência necessários para obter o rendimento adequado às politicas e nos prazos previstos (HALL; MEJÍA, 1978, p.10-11).

No Brasil, a década de 1970 representou o momento de início e desenvolvimento do movimento sanitário, que propôs profundas reformas no modo de organizar e prestar a assistência à saúde à população brasileira. $\mathrm{O}$ contexto era de crise econômica, social e política, em grande parte, devido à política desenvolvimentista e ao endividamento externo, contraído para o processo de industrialização dos anos 1950 (TOLEDO, 1984).

Naquele contexto, marcado pelo autoritarismo do regime militar, o Brasil elaborava planos nacionais de desenvolvimento centralizados (1972 e 1974) e buscava implantar um Sistema Nacional de Saúde para ampliar a cobertura da atenção médica individualizada. Nesse sentido, planejar RHS, no Brasil, significava dispor de profissionais de saúde adequados para estender os serviços de saúde a uma população antes não assistida.

Desde a década anterior, durante a realização da $3^{\text {a }}$ Conferência Nacional de Saúde (CNS), a necessidade de planejar o número adequado de profissionais às exigências e necessidades do sistema público de saúde e ao crescente setor privado já havia sido identificada como problema. A distribuição equitativa de médicos nos municípios e regiōes do país era uma preocupação, como expressam trechos dos anais da Conferência:

[...] o preparo de pessoal [...] deve obedecer a uma política planejada de aproveitamento. Inuitil produzir mais que as necessidades do consumo, mormente em se tratando da custosa preparação técnica do homem. Como vai ser resolvida a presença de médicos nos municipios? Seria ingenuidade pretender mandar médicos em grande número para o interior. Náo só no Brasil, como no mundo inteiro, o que se vem verificando é a concentração cada dia maior de profissionais de medicina nos grandes centros (BRASIL, 1993, p. 20). 
Ainda ao final dos anos 1960, técnicas de projeção do potencial humano eram debatidas na $4^{\mathrm{a}} \mathrm{CNS}$, e as análises sinalizavam a inadequação de modelos utilizados nos países desenvolvidos aos países em desenvolvimento, dadas as diferenças das estruturas social, demográfica e econômica. A formação de pessoal para ocupar o setor saúde estava, portanto, relacionada à ideia do quantitativo necessário para os programas em execução. Era prevista, inclusive para os casos de rápida necessidade de expansão dos serviços, a admissão de pessoal, com formação elementar, para as regióes com dificuldades para empregar médicos.

Com políticas de saúde que priorizavam a expansão do setor privado e financiavam, com recursos públicos, a construção e a reforma de inúmeras clínicas e hospitais privados, e com políticas de convênios entre o Instituto Nacional de Previdência Social e os hospitais, clínicas e empresas de prestação de serviços médicos (LUZ, 1991), os desdobramentos da preocupação com a adequação da força de trabalho à expansão desses serviços para o setor público caracterizaram-se pelas orientaçôes no sentido de formar pessoal de nível elementar, essencialmente, como práticos, em treinamentos breves, para ocupar regióes para as quais médicos com formação 'custosa' não estariam disponíveis.

O plano econômico, antes de qualquer outro, dava sentido à necessidade de planejamento de recursos humanos, considerados como 'capital humano' pelos governos daquele período.

O planejamento consiste, em última análise, na elaboração de um conjunto de meios para aplicá-los a um conjunto de objetivos determinados. Admitido o pressuposto de que os objetivos, no campo da saúde estão definidos e quantificados, impóe-se eleger e avaliar os recursos humanos e materiais necessários a que sejam plenamente alcançados (BRASIL, 1993, p. 25).

É possível identificar a noção de 'recursos humanos', no mesmo nível dos recursos materiais, como mais um dos meios a serem administrados para um determinado fim. Desconsidera-se que tais 'recursos' tratem-se, na realidade, de sujeitos que transformam e movimentam a história, e que, portanto, devam ser integrados ao processo de planejamento e gestão. $\mathrm{O}$ conceito 'recursos humanos' abstrai os trabalhadores de saúde de suas relações sociais, historicamente determinadas, obscurecendo as contradiçóes e os conflitos do próprio sistema econômico no qual estão inseridos, sendo, portanto, adequado ao enfoque normativo.

Em 1974, foi instituído um grupo de trabalho interministerial cujo relatório propôs um programa com projetos voltados a três áreas de ação, sob responsabilidade do Ministério da Saúde (MS): i) planejamento de recursos humanos; ii) preparação direta de pessoal para a saúde; e iii) apoio ao desenvolvimento do programa nacional de preparação e distribuição estratégica de pessoal de saúde. As metas previstas para formação de pessoal de nível médio (técnico e auxiliar) e elementar foram de 160.000 a 180.000 , para o período de 1976 a 1979, com dimensionamento elaborado para cada região, de acordo com as necessidades e possibilidades identificadas (OPAS, 1976).

A preocupação voltada para a quantidade de médicos pode ter sido decorrente do modelo de expansão de serviços de atenção médica previdenciária, principalmente para os centros urbanos, incluindo recursos para a construção de hospitais privados do Fundo de Apoio ao Desenvolvimento Social (1974), que exigia esses profissionais devido ao modelo de atenção. Para o Nordeste do país, região com número insuficiente de médicos, pretendia-se estender serviços de atenção básica, como o Programa de Interiorização das Ações de Saúde e Saneamento (1976), para os quais era orientada a formação de profissionais de nível elementar, em cursos mais curtos, e, preferencialmente, quando já inseridos no trabalho.

No Brasil, pode-se dizer que a primeira experiência relacionada com os propósitos do planejamento de RHS foi o Programa de Preparação Estratégica de Pessoal da Saúde (PPREPS), em 1976, cujo objetivo central era o de promover, tanto em termos quantitativos como qualitativos, a adequação da formação de recursos humanos, em todos os níveis, às necessidades dos serviços de saúde. Os motivos para sua proposição foram a constatação de distorçôes entre os 'estoques de recursos humanos' para o setor e a oferta prevista para os anos seguintes; a falta de integração entre os setores 
de formação e de serviços; e a possibilidade de expansão dos serviços públicos (OPAS, 1976).

Na 6a CNS, em 1977, observou-se uma renovação conceitual e uma visão mais abrangente da questão dos RHS do que até então vigorara. Foram abordadas questóes relativas à gestão do trabalho, como regime de trabalho e incentivos funcionais, além dos temas já debatidos sobre formação, qualificaçâo e preparação de pessoal para a execução adequada dos programas e projetos estabelecidos (BRASIL, 1993).

Na década de 1970, a OPAS foi uma das principais fontes de desenvolvimento de metodologias e projetos voltados à capacitação de especialistas em planejamento, disseminando a ideia de que, a partir de métodos adequados de planejamento, os países poderiam alcançar objetivos e metas definidos segundo diagnósticos bem elaborados. Para tanto, sugeria a necessidade da informação estatística e da formação de especialistas e de unidades especialmente voltadas para a elaboração de planos no interior dos ministérios de saúde (PIRESALVES; PAIVA, 2006).

Do ponto de vista político, pode-se dedicar a falta de resultados de médio e longo prazos dos planos elaborados à crise do planejamento estatal, reflexo da própria crise do papel do Estado na sociedade capitalista e do fortalecimento do modelo neoliberal nas décadas seguintes. A questão metodológica do processo de planejamento foi enfatizada, porém, como assinala Onocko-Campos (2000, p. 725): “o que fazer' é sempre anterior ao 'como fazer', e esse 'o que fazer' não é dado a priori”.

\section{A década de 1980: crise do planeja- mento estatal e o enfoque estratégico}

Nos contextos social e econômico internacionais, de modo distinto do que ocorria anteriormente - quando predominavam as concentraçóes operárias numa mesma fábrica, cidade, região ou país, e se expandiam os sistemas de seguridade social -, as medidas neoliberais, em curso nos países centrais, priorizaram a desterritorialização do trabalho e das mercadorias e a precarização das condiçóes e relaçóes de trabalho, impactando as condiçóes de vida dos trabalhadores e sua capacidade de organização e resistência (MOTA, 2009).

Nesta década, já se iniciava, no Brasil, o processo de reestruturação produtiva (com a informatização), os programas de qualidade total e a implantação de métodos de 'gestão participativa', inicialmente marcada pela redução de postos de trabalho e pela ampliação da jornada de trabalho para aumentar a produtividade, processo este intensificado nos anos 1990 (MOTA, 2009).

Durante muitos anos, o planejamento de recursos humanos foi um componente importante de cooperação entre os Programas de Desenvolvimento de Recursos Humanos da OPAS e da OMS, e era compreendido como a busca de um equilíbrio entre a oferta e a demanda de pessoal nos sistemas de saúde. E, apesar de, aparentemente, 'técnicos' e 'neutros', os cálculos padronizados originaram-se da pressão política de corporaçóes profissionais ou da preocupação de gestores em conjunturas marcadas por ciclos de superoferta ou escassez de pessoal (QUINTANA; RÍGOLI; PADILHA, 2002).

Ao ignorar as condiçôes políticas, econômicas e sociais, indutoras das necessidades e ofertas da força de trabalho - como o retorno político de abertura de novos cursos de medicina, independentemente das necessidades do sistema de saúde; a defesa corporativa de algumas profissóes; a expansão de vagas em instituiçóes privadas, com o objetivo básico de retorno econômico -, o enfoque normativo as 'naturaliza', tomando-as como imutáveis. Ou seja, para esse enfoque, o planejamento da FTS deve encontrar a melhor distribuição da oferta, de acordo com a demanda e, preferencialmente, adequando-se à realidade já existente (QUINTANA; RÍGOLI; PADILHA, 2002).

Em meados dos anos 1980, surgiram as teorias de planejamento estratégico e situacional, como alternativa aos problemas de inefetividade do enfoque normativo. A OPAS promoveu o desenvolvimento de novas abordagens do planejamento de pessoal, que consideravam as dimensóes políticas, a instabilidade, as incertezas e a complexidade do campo sanitário e do campo de recursos humanos como condicionantes do processo de planejamento e dos objetivos e componentes do plano (QUINTANA; RÍGOLI; PADILHA, 2002). 
Em 1984, a partir das produçóes de Barrenechea e Trujillo, embasados nos estudos de Carlos Matus, Mario Testa, Paulo Mota e do Instituto Latino-Americano de Planejamento Econômico e Social (ILPES), a OPAS organizou diversas reuniōes - com a participação das Escolas de Saúde Pública do Rio de Janeiro, Medellín, México e Buenos Aires - para discutir o tema do planejamento estratégico. Quase simultaneamente, em 1985, esse grupo teve contato com as discussóes do Programa Regional de Desenvolvimento de Pessoal de Saúde, da OPAS, e, em conjunto, organizaram vários seminários sobre as experiências de planejamento para as secretarias de saúde, no fim da década de 1980 e início de 1990, em países da América Latina, como Argentina, Peru' ${ }^{1}$ e Brasil (ROVERE, 2006 ).

Esses avanços não foram percebidos nos debates referentes à política de desenvolvimento de recursos humanos da $7^{\text {a }}$ CNS, em 1980, que enfatizaram, unicamente, a formação de profissionais adequados à organização dos serviços básicos de saúde, e consideraram os recursos humanos meios para alcançar os objetivos propostos por tais programas. Assim, aspectos relacionados à ênfase na especialização médica e na necessidade de formação de profissionais de nível médio e elementar centralizaram o debate (BRASIL, 1993).

Em 1986, foi realizada a $8^{\text {a }} \mathrm{CNS}$, na qual as deliberações acerca da política de recursos humanos abrangeram aspectos relacionados à gestão, como valorização da dedicação exclusiva ao sistema público, remuneração e plano de cargos e carreiras, constituição de equipes multiprofissionais de acordo com as necessidades da demanda, critérios de cobertura e aspectos relacionados à formação e à qualificação dos profissionais para atuação em um novo modelo de assistência, a ser implantado com a instituição do SUS (BRASIL, 1993).

Neste ano, também foi realizada a $1^{\text {a }}$ Conferência Nacional de Recursos Humanos para a Saúde, que teve como tema central a 'Política de Recursos Humanos rumo à Reforma Sanitária', dando continuidade aos

${ }^{1}$ Apesar das experiências de planejamento da força de trabalho dos anos de 1980, o Peru é, atualmente, um dos países da América Latina com escassez de profissionais de saúde.. debates da $8^{\text {a }}$ CNS. A necessária articulação entre as instituições formadoras e as de prestação de serviços foi enfatizada nessa ocasião, mas salientou-se que, além das questôes referentes à formação, os problemas relativos à gestão, como recrutamento e seleção, concurso, plano de cargos e salários, isonomia salarial, avaliação de desempenho, direitos trabalhistas, entre outros, deveriam ser incorporados às discussóes sobre recursos humanos. Também considerou-se que a composição, capacitação e organização das equipes deveriam ser planejadas segundo o diagnóstico das necessidades de saúde da população; já os parâmetros usados para distribuição dos profissionais, segundo o número de leitos, população etc., deveriam ser revistos (BRASIL, 1993).

No texto intitulado A questão dos recursos humanos e a reforma sanitária, redigido, em 1987, pelo grupo de trabalho de Recursos Humanos da Comissão Nacional de Reforma Sanitária ${ }^{2}$, foram apresentados alguns dos obstáculos para a consolidação da universalização da cobertura e da garantia de equidade das açóes de saúde no processo da construção do Sistema Único de Saúde: a distribuição geográfico-social e institucional dos recursos humanos, que concentrava 56\% dos empregos de saúde na região Sudeste e apenas 20\% na regiấo Nordeste; a desigualdade das condiçóes de inserção no mercado de trabalho (segmentação); a formação e a preparação dos recursos humanos; a composição das equipes de saúde, pois de 60 a $70 \%$ do pessoal ocupado nos estabelecimentos de saúde eram formados por médicos e atendentes; e a valorização do profissional (BRASIL, 1993).

Quanto às condições de inserção no mercado de trabalho, esse grupo defendeu a unificação de todos os empregos em uma única modalidade contratual, com isonomia plena de remuneração, direitos e deveres. Para tanto, apontava para a vinculação dos trabalhadores à esfera de gestão responsável pela atividade

${ }^{2} \mathrm{O}$ grupo foi constituído por Francisco Eduardo Campos (coordenador), Francisco Lopes, Joana Azevedo da Silva, José Francisco Nogueira P. de Santana, Marcelo Torres Teixeira Leite, Maria Cristina Fekete, Maria José R. Rossi e Sábado Nicolau Girardi. 
exercida, resguardando-se a normatização central para assegurar a uniformidade do sistema, que pretendia unicidade de princípios e diretrizes. Já indicava, também, a necessidade de grandes alteraçóes na legislação do exercício dos profissionais de saúde, cuja jornada de trabalho possibilitava a acumulação de empregos, dificultando a viabilização da adscrição de clientela e vínculo (BRASIL, 1993).

Após a $8^{\text {a }} \mathrm{CNS}$, são incorporadas à Constituição Federal, em 1988, praticamente todas as recomendaçóes aprovadas naquele fórum (BRASIL, 1993). No artigo 200, inciso III, da Constituição Federal de 1988, ficou estabelecido que competia ao SUS, além de outras atribuiçōes, 'ordenar a formação de recursos humanos na área de saúde'. No entanto, as dificuldades inerentes à regulamentação desse dispositivo constitucional relacionam-se à prerrogativa de autonomia universitária, legalmente garantida pelo art. 207 da Constituição Federal. Apesar das tentativas, a regulamentação desse artigo, em 1992, por meio do Projeto de Lei do Senado no 137 e, em 2002, do Projeto de Lei no 6.240, na Câmara dos Deputados, foi rejeitada, alegando-se o caráter inconstitucional de impor condicionantes para a criação de vagas nas universidades, ferindo o princípio da autonomia (ROMERO, 2008).

Em análise da produção científica acerca da política, do planejamento e da gestão em saúde, Paim e Teixeira (2006) observaram que, nesta década, apareceram estudos sobre programas de extensão de cobertura, de formação e capacitação de pessoal e experiências de integração docente-assistencial. A elaboração e a implantação de propostas de reforma na gestão, planejamento e organização dos serviços e o interesse pelas questóes teórico-metodológicas no campo do planejamento e da gestão também foram observadas pelos autores. E, no campo das políticas de recursos humanos, iniciava-se uma discussão a respeito do processo de trabalho em saúde e das relaçóes sociais que permeiam a produção dos serviços de saúde e das práticas e atitudes institucionais que condicionavam essas relaçóes.

Essas discussóes possibilitam a emergência da crítica ao termo 'recursos humanos' e a defesa do conceito da 'força de trabalho em saúde', o que possibilita analisar o conjunto dos trabalhadores de saúde, segundo a 'capacidade de realizar trabalho útil que aumenta o valor das mercadorias' (BOTTOMORE, 1988). Além disso, apesar de a força de trabalho também se transformar em mercadoria, no modo capitalista de produção, ela possui características que, ao mesmo tempo que a distinguem das outras mercadorias, expressam importantes contradiçóes nesse sistema:

Em primeiro lugar, [...] a força de trabalho
não é produzida como as outras mercadorias.
[...] Em segundo lugar, o valor de uso da força
de trabalho é a sua capacidade de produzir va-
lor. (Portanto) [...] a extraçáo de trabalho da
força de trabalho cria outros pontos de conflito
entre o comprador (o capitalista) e o vendedor
(o operário) [...] trata-se dos conflitos sobre a
intensidade e as condiçóes de trabalho (que)
estruturam fundamentalmente os aspectos téc-
nicos e sociais da produçáo capitalista. Final-
mente, a venda da força de trabalho aliena o
trabalhador da sua capacidade criativa de pro-
duçâo e [...] do produto desse trabalho (BOT-
TOMORE, 1988, 231-232).

TOMORE, 1988, 231-232).

Nesse sentido, trazer à tona as contradiçóes e os conflitos inerentes ao trabalho e ao conjunto dos trabalhadores de saúde, inseridos em um modo de produção capitalista, contribui para desvelar a relação entre as políticas econômicas, sociais e de saúde e a prática do planejamento. Além disso, conforme defendem Quintana; Rígoli; Padilha (2002), a viabilidade política do plano se assegura, em grande parte, pelo envolvimento e pela participação ativa dos sujeitos - trabalhadores e não 'recursos'- a partir da definição das questôes políticas a serem enfrentadas e das questôes estratégicas para a implantação e a avaliação desse mesmo plano.

Na década de 1980, emergiram importantes contribuiçốes no plano teórico-conceitual, com impactos na legislação sanitária em vigor, tais como a crítica ao enfoque normativo do planejamento de recursos humanos na saúde e as discussões acerca do processo de trabalho em saúde, que, aliás, auxiliam a explicitar a dimensão política dos problemas a serem enfrentados nesse campo até aos dias de hoje. 


\section{A década de 1990: Estado omisso, pla- nejamento ausente}

No Brasil, a década de 1990 foi marcada por um quadro de retrocesso das conquistas sociais da década anterior. A redefinição do papel do Estado, no tocante à prestação de serviços, desfazendo-se de responsabilidades assumidas nos anos anteriores, evidenciou-se como consequência das imposiçóes macroeconômicas, expressas pelas orientações de organismos financeiros internacionais e alcançadas por meio de processos de privatização, desregulação e terceirização. Essas reformas administrativas do Estado, por sua vez, repercutiram no mundo do trabalho, desencadeando um aumento do desemprego e a precarização do trabalho (NORONHA; SOARES, 2001; VARELLA; PIERANTONI, 2008; PEREIRA, 2004).

Os primeiros dez anos de vigência das reformas setoriais, denominadas de 'reformas de primeira geração', na maioria dos países, concentraram-se nas mudanças da estrutura dos sistemas (descentralizaçáo) e no seu financiamento, assim como na redefinição das responsabilidades e funçóes do Estado para a saúde, na separação de funçóes, na mercantilização da saúde, nas mudanças dos modelos de gestão e na privatização dos serviços de saúde (QUINTANA; RÍGOLI; PADILHA, 2002).

Essas reformas também foram implantadas em outros países da América Latina - com graves consequências sociais - em nome de uma suposta 'modernização' e adaptação dos países 'em desenvolvimento' à dinâmica do capitalismo contemporâneo. A área social, incluindo a da saúde, em função da sua relação direta com as condições econômicas de restrição financeira, impostas pelas políticas de ajuste econômico, viu velhos problemas se agravarem e novos surgirem. A capacidade de resposta do Estado aos problemas sociais tornou-se cada vez menos efetiva frente às crescentes demandas, criando condiçóes para uma onda de terceirizaçôes e privatizaçôes de várias formas (NORONHA; SOARES, 2001; VARELLA; PIERANTONI, 2008; PEREIRA, 2004).

No setor saúde, ao contrário do observado no mercado de trabalho, em geral, houve expansão do número de postos de trabalho e aumento do número de ocupaçôes, com a incorporação de diversos outros trabalhadores, que não eram necessariamente profissionais de saúde (administradores, técnicos de outras áreas, pessoal auxiliar etc.). A implantação do SUS traduziuse em grande alavanca desse mercado, expressa pela expansão dos serviços básicos da rede pública e dos contratos com a rede privada. Apesar do crescimento quantitativo de empregos no setor, o que se observou foram decréscimos qualitativos nas relaçóes contratuais, como o aumento dos vínculos temporários, da quantidade de autônomos e de empregos desregulamentados, da destituição de direitos trabalhistas e da diminuição dos níveis de proteção social, inclusive no setor público, e dos poucos avanços salariais que caracterizaram o mercado de trabalho em saúde dos anos 1990 (VARELLA; PIERANTONI, 2008; PEREIRA, 2004).

Para a FTS, o comprometimento do potencial político-organizativo dos trabalhadores apresentou-se como uma das mais graves consequências das medidas neoliberais, intensificadas, no Brasil, a partir da década de 1990. Essa desorganização política dos trabalhadores, observada no setor da saúde, deveu-se, entre outros fatores, às novas formas de gestão do trabalho, que promoveram o aumento do número de profissionais contratados como autônomos, as terceirizaçóes das atividades de limpeza, higienização e esterilização de materiais, o incentivo às modalidades de atendimento domiciliar do tipo home care, ofertadas por cooperativas, além do incentivo à organização de seguros e planos privados disponibilizados por grupos de profissionais de saúde 'liberais', criando-se, com isso, um mosaico de situações jurídicas e profissionais que tornaram menos visíveis os laços existentes entre os trabalhadores (MOTA, 2009).

Nas diversas modalidades de terceirização ocorridas nesse período, o Estado transferiu para entidades privadas não só a responsabilidade de gerenciar e prestar serviços, mas também os recursos públicos - imóveis, equipamentos e força de trabalho - para que as mesmas executassem os serviços. À medida que se desmontava quase toda a estrutura pública para provisão dos serviços de saúde, entregando-a nas mãos de terceiros, desmontava-se, também, a capacidade de organização e mobilização política dos trabalhadores de saúde, para resistirem a esse quadro de retrocesso durante a construção do SUS (PEREIRA, 2004). 
Da mesma forma, o processo de municipalização e suas repercussões para a FTS condicionaram o aumento dos vínculos de trabalho com os municípios; na segunda metade da década de 1990, o Programa de Saúde da Família (PSF) caracterizou-se como o principal mecanismo de inserção de trabalhadores de saúde por meio de contratos precarizados com Organizaçóes Não Governamentais (ONGs), Organizações da Sociedade Civil de Interesse Público (OSCIPs), cooperativas e empresas terceirizadas para esse nível da gestão do sistema de saúde. A forma contratual estatutária para inserção de médicos e enfermeiros na Atenção Básica chegou a $22 \%$ e $25 \%$, respectivamente, nesse período (VARELLA; PIERANTONI, 2008; PEREIRA, 2004).

Esse processo de privatização da saúde comprometeu o conjunto do sistema, incluindo o planejamento e a gestão do trabalho, na medida em que implicou a vinculação das decisóes próprias do campo da saúde aos interesses empresariais de análises de custo-benefício, em detrimento da lógica dos direitos humanos e das necessidades inalienáveis (BREILH, 2006).

É necessário destacar, aqui, que a precarização dos vínculos de trabalho compromete a relação dos trabalhadores de saúde com o sistema, prejudica a qualidade e a continuidade dos serviços prestados, em razão de consequências como a alta rotatividade de profissionais e a impossibilidade de se efetivarem processos de planejamento de médio e longo prazos. O MS identificou, entre 2001 e 2002, na Estratégia Saúde da Família, variadas formas de vínculo dos trabalhadores municipais dessas equipes: estatutários e celetistas (em menor proporção: aproximadamente, 13\%), temporários, comissionados, bolsistas, prestadores, cooperados, além dos contratos informais e verbais (BRASIL, 2006).

Conforme destacam Quintana; Rígoli; Padilha (2002), observaram-se, também, a persistência e o agravamento de problemas relativos à disponibilidade, à distribuição e à estrutura da FTS, além do subfinanciamento dos serviços de saúde e das mudanças na regulação do trabalho e nos modelos de atenção e gestão. Tais condições, mantidas e agravadas pelas reformas do Estado e da administração pública, ocorridas na década de 1990, foram, de fato, profundas reformas na ordem laboral no setor saúde e nas estruturas e processos do trabalho.
Os setores de governo que, limitadamente, executavam alguma política de planejamento e regulação do trabalho praticamente desapareceram ou foram reduzidos a uma expressão simbólica dentro das organizaçóes. Essas práticas foram, em grande parte, substituídas pelos projetos de apoio às reformas, elaborados por instâncias dos organismos internacionais de financiamento que, ao conceberem determinados projetos, projetavam o pessoal adequado aos seus objetivos (QUINTANA; RÍGOLI; PADILHA, 2002).

Algumas práticas de planejamento, que persistiram na realidade dos serviços, demandavam indicadores e parâmetros internacionais sobre a proporção de profissionais por número de habitantes (médicos e enfermeiras) ou por número de leitos, sobre a relação entre as categorias profissionais e um determinado nível de atenção, ou mesmo demandavam métodos e técnicas para cálculo de dotação ideal de profissionais por estabelecimentos de saúde. Consequentemente, os avanços no processo de planejamento, a partir das teorias estratégica e situacional, ocorreram mais no campo conceitual que no operacional (QUINTANA; RÍGOLI; PADILHA, 2002).

Nessa década, além da realização das $9^{a}$ e $10^{a}$ CNS, em 1992 e 1996, realizou-se, também, a 2a Conferência Nacional de Recursos Humanos para a Saúde, em 1993, que confirmou, nos debates, os efeitos perversos de tais políticas macroeconômicas para o setor saúde, em especial, para os trabalhadores da saúde, indicando que a política de RHS não havia se alterado positivamente após a criação do SUS (BRASIL, 1993).

A descentralização dos serviços de saúde também trouxe implicaçóes para o planejamento, pois os municípios assumiram a responsabilidade de traduzir os objetivos relativos à assistência de saúde em metas de recursos humanos, tanto quantitativas quanto qualitativas, em termos de competência e resolutividade, e o modelo de atenção definido deveria contar com uma clara política desses recursos (QUINTANA; RÍGOLI; PADILHA, 2002).

A municipalização dos serviços de saúde, porém, não conseguiu impulsionar a prática do planejamento ascendente, porque desencadeava em um momento de recuo do poder público quanto aos processos de gestão, 
organização e provisão dos serviços. Também a expansão dos serviços e dos postos de trabalho, a partir das determinações legais para o sistema de saúde, não foi acompanhada de planejamento no interior das secretarias municipais de saúde; esse tema foi retomado apenas posteriormente, no início dos anos 2000.

Assim, de acordo com Machado (2006), a década de 1990 pode ser caracterizada pelo abandono da proposta de planos de carreira profissional, pela precarização do trabalho no SUS, pelo crescimento 'anárquico' e sem relação com as necessidades sociais do SUS (por parte das escolas de saúde) e pela desmobilização do movimento sindical. Em outras palavras, para a autora, essa pode ser considerada a 'década perdida para os recursos humanos em saúde', e seu saldo político 'uma enorme dívida social para com os trabalhadores'.

\section{Os anos 2000: a retomada do planejamento}

As transformaçóes do modelo de desenvolvimento e da sociedade brasileira exigidas para o enfrentamento de distorçôes estruturais do sistema de saúde e consolidação do SUS não foram realizadas, portanto, na década anterior, em virtude das reformas administrativas do Estado, que se ausentou de áreas importantes para as políticas sociais (MACHADO; BAPTISTA; NOGUEIRA, 2011).

O agravamento dos problemas envolvendo a FTS, porém, resultou da coexistência de situaçóes recentes - as formas de contratação, tipos de vínculo e mecanismos de remuneração, como reflexo das mudanças ocorridas no mundo e na América Latina, na década anterior - e antigas - como a deficiência de pessoal qualificado, a distribuição desigual da força de trabalho no país, o desequilíbrio entre a oferta e a demanda nos serviços públicos, principalmente de profissionais médicos -, identificadas desde os anos 1970.

Foi apenas em 2001 que, pela primeira vez em vinte anos, o Conselho Diretor da OPAS-OMS pôde se referir, de maneira explícita e ampla, ao tema de políticas e gestão de recursos humanos em saúde e convocar os demais setores para priorizar as políticas de recursos humanos em geral e para fortalecer, de maneira específica, a gestão de recursos humanos para os serviços de saúde (QUINTANA; RÍGOLI; PADILHA, 2002).

Em 2005, com a 7a Reunião Regional dos Observatórios de Recursos Humanos em Saúde, realizada em Toronto (Canadá) e promovida pela OPAS, elaborou-se o documento denominado 'Chamado à ação de Toronto: 2006-2015 rumo a uma década de recursos humanos em saúde nas Américas' e considerado um marco da formulação e implantação dos planos de recursos humanos desse período (BRASIL, 2006a).

Esse documento apresenta alguns princípios que embasam a necessidade de envidar esforços de longo prazo para a promoçáo, o fortalecimento e o desenvolvimento da FTS em todas as regiôes das Américas. Enfatiza, também, a questão da formação/capacitação técnica tanto de gestores, para uma liderança mais efetiva, como dos trabalhadores de saúde, para uma atuação adequada às mudanças previstas nos sistemas de saúde e ao modelo de atenção universal, equitativo e de qualidade. Apresenta, ainda, a distribuição quantitativa de profissionais de saúde, com observaçóes sobre as necessidades de saúde das regiōes e a necessária sustentabilidade dos planos quanto ao financiamento e à mobilização/sensibilização da comunidade internacional, para que se mantenha o interesse em torno dos recursos humanos e da produção de informaçáo e conhecimento sobre a importância dos recursos humanos na saúde.

Nesse sentido, observa-se que a centralização nos temas sobre formação adequada e capacitação técnica mantém-se atual no que diz respeito às discussóes referentes à FTS por organismos internacionais, e que os aspectos relacionados ao processo de trabalho e à gestão do trabalho, como a precarização dos vínculos, permanecem secundarizados, em um contexto para o qual a lógica do mercado impede o planejamento da força de trabalho voltada a atender às necessidades e os direitos da maioria da população.

De acordo com dados publicados por Silveira et al. (2010), em estudo realizado nesta década, 38\% dos trabalhadores da rede de atenção básica, de 21 municípios da região Sul e 20 municípios da região Nordeste, possuem vínculos precários de trabalho; menos da metade $(40 \%)$ desses trabalhadores ingressou por meio de 
concurso público; somente $16 \%$ referiram ter acesso a plano de carreiras, cargos e salários (PCCS); e cerca de $20 \%$ relataram ter outro emprego, sendo que essa proporção variou de $2 \%$ (para os agentes comunitários de saúde) a $69 \%$ (para os médicos).

A precarização dos vínculos de trabalho ainda é um dos principais motivos da elevada rotatividade de profissionais médicos e enfermeiros na atençâo básica, o que compromete o planejamento da força de trabalho. Em municípios da região Sul, conforme apresentado por Medeiros et al. (2010), os profissionais pesquisados mencionaram: a influência político-partidária nas definiçóes inerentes aos projetos de trabalho das equipes; a especialização na formação; o estilo de gestão autoritário; a ausência de vínculos com a comunidade; e as más condições de trabalho, aliadas a outras oportunidades mais atraentes do mercado, como desencadeadores da rotatividade nesse nível da atenção. Os autores perceberam nos relatos que o vínculo empregatício precário poderia ser usado como instrumento de controle político sobre as equipes de saúde das famílias pesquisadas.

Esse contexto de precarização dos vínculos de trabalho e outras condições insatisfatórias para o desenvolvimento do trabalho no setor saúde forçaram a aprovação da Norma Operacional Básica de Recursos Humanos para o SUS (NOB-RH-SUS), discutida e reformulada há vários anos ${ }^{3}$. Em 2003, o Conselho Nacional de Saúde aprovou sua aplicação como Política Nacional de Gestão do Trabalho e de Educação na Saúde, tendo em vista que a norma sistematiza e formaliza as propostas deliberadas nas conferências nacionais de saúde e nas conferências temáticas relativas aos recursos humanos em saúde. Com relação ao processo de planejamento de recursos humanos, foi enfatizada a necessidade de criação de bancos de dados nas três instâncias de gestão, para possibilitar ações de planejamento de acordo com a realidade (BRASIL, 2005).

Também em 2003, o MS instituiu, a partir das discussões da Mesa Nacional de Negociação

\footnotetext{
${ }^{2}$ A primeira versão da NOB-RH-SUS foi elaborada em 1998 e a segunda foi publicada em 2000; a primeira impressão da $3^{a}$ edição ocorreu em 2004.
}

Permanente, o Comitê Nacional Interinstitucional de Desprecarização do Trabalho no SUS, que ampliou o debate nacional sobre a necessidade reverter a situação de precarização de vínculos de trabalho no sistema de saúde (BRASIL, 2006b).

Naquele mesmo ano, foi criada a Secretaria de Gestão do Trabalho e da Educação em Saúde (SGTES), com o objetivo de formular políticas orientadoras da gestão, formação, qualificação e regulação dos trabalhadores da saúde no Brasil (BRASIL, 2011). A mudança na denominação da área - de 'recursos humanos em saúde' para 'gestão do trabalho e da educação em saúde' -, no âmbito do MS, possivelmente foi um reflexo dos diversos debates que ocorreram em torno desses conceitos desde a década de 1980 (ROVERE, 2006; ASSUNÇÃO et al. 2007), e que conseguiram visibilidade com a eleição de outro governo no país, em 2003, que assumia o poder defendendo mudanças na área social.

Na primeira década deste século, foram realizadas: a $11^{\text {a }} \mathrm{CNS}$, em 2000, que debateu o acesso, o acolhimento e a humanização na atenção à saúde, além de aprovar o documento NOB-RH-SUS; a $12^{\text {a }} \mathrm{CNS}$, no ano de 2003, que analisou o contexto em que se realizava a Conferência e reafirmou o dever do Estado e o ideário do SUS; e a $13^{\text {a }}$ CNS, em 2008 , que propôs a discussão das políticas de Estado e desenvolvimento. A $3^{\text {a }}$ Conferência Nacional de Gestão do Trabalho e da Educação na Saúde, realizada em 2006, produziu e divulgou textos de apoio para o debate com importantes dados sobre essa política no Brasil.

A partir da criação da SGTES, várias açóes foram desencadeadas no sentido de implementar as propostas aprovadas desde a $8^{a}$ Conferência Nacional de Saúde e a $1^{\text {a }}$ Conferência de Recursos Humanos em Saúde. A partir de 2006, entre as ações promovidas pelo Departamento de Gestão e da Regulação do Trabalho em Saúde (DEGERTS), no Programa de Qualificação e Estruturação da Gestão do Trabalho e da Educação no SUS (ProgeSUS), estão: a criação de bancos de dados e de um sistema de informaçóes sobre a força de trabalho de saúde no país - Sistema Nacional de Informaçóes em Gestão do Trabalho do SUS (INFORSUS) e o Sistema de Informaçóes sobre os Conselhos Profissionais (CONPROF) (BRASIL, 2011). 
Como exemplo da retomada das discussóes sobre a FTS, no Brasil, outras açóes desencadeadas pela SGTES foram: i) a criação do Programa Nacional de Desprecarização do Trabalho no SUS - DesprecarizaSUS, com o intuito de buscar soluçôes para a precarização dos vínculos de trabalho nas três esferas de governo; ii) a instituição do Fórum Permanente Mercosul para o Trabalho em Saúde, com o objetivo de formular políticas de gestão do trabalho e da educação na saúde que levem a uma maior cobertura e maior qualidade da atenção à saúde para a população, prioritariamente, nas regióes fronteiriças do Mercosul; iii) a discussão para implementação do PCCS-SUS; iv) na área da gestão da formação, a criação dos programas PET-Saúde, Profae, Profaps, Pró-saúde, Pró-residências, Telessaúde e UnaSUS; v) a instituição da Câmara de Regulação do Trabalho na Saúde (CRTS) como instância permanente de resgate do papel do gestor e regulador do trabalho em saúde. Esses programas e açôes merecem análises aprofundadas para avaliar os avanços e limites de cada proposta.

Quanto ao planejamento em saúde, o MS instituiu o Sistema de Planejamento do SUS (PlanejaSUS), por meio da Portaria no 3.085 , de $1^{\circ}$ de dezembro de 2006. Como principal desafio, o MS apontou para a construção da cultura de planejamento no SUS, 'sobretudo se se considerar o curto período do processo em curso e o esvaziamento - talvez até mesmo distorção - que esta funçáo experimentou ao longo das últimas décadas na administração públicá. Como resultados iniciais, o MS indicou a divulgação dos instrumentos básicos para o planejamento (plano de saúde, programação e relatório de gestão), por meio das oficinas realizadas em abril e maio de 2008, e a organização e publicação de uma série 'Cadernos de Planejamento', com 9 volumes, além do livro PlanejaSUS: trajetória e orientações de operacionalização, disponíveis online (BRASIL, 2006c).

No ano de 2007, foi aprovada a Portaria no 1.318, que 'publica as Diretrizes Nacionais para a instituição ou reformulaçãa de Planos de Carreiras, Cargos e Salários, a título de subsídios técnicos à instituição de regime jurídico de pessoal no âmbito do Sistema Único de Saúde, que se recomendam a seus gestores, respeitada a legislação de cada ente da Federação' (BRASIL,
2007). Essa medida congrega as iniciativas da SGTES, que, juntamente com as estratégias destinadas à desprecarização do trabalho e as mesas de negociaçáo permanentes, são necessárias para a reversão dos problemas evidenciados na década anterior. Estudos mais aprofundados sobre o atual processo de implantação, avanços e obstáculos, assim como alguns resultados dessas políticas, poderão ser realizados futuramente, para sugerir aprimoramentos em direção à consolidação das diretrizes indicadas pela Política Nacional de Gestão do Trabalho e da Educação, a NOB-RH-SUS.

\section{Considerações finais}

Apesar de atual, não são novos os problemas, amplamente difundidos na mídia, sobre a falta de médicos em determinadas regiōes do país, a desarticulação entre a formação e a oferta de profissionais e as necessidades do sistema de saúde e direitos da população. Decorrentes da ausência de uma política de planejamento da força de trabalho para o SUS, esse quadro tem sido uma das consequências da opção do Estado, nas duas décadas de existência do SUS, de ter subsidiado os interesses de setores privados, vinculados ao mercado da saúde - ou indústria da doença.

Ao se analisar, historicamente, as políticas de saúde voltadas à gestáo e ao planejamento da força de trabalho no contexto pós-constitucional, é possível identificar que o Estado se omitiu das questôes relacionadas aos trabalhadores de saúde que compóem o SUS - desde a formação até a distribuição desses trabalhadores pelo sistema de saúde, mediante as necessidades prioritárias e os direitos sociais e de saúde conquistados pela população e indicados regularmente em todas as conferências de saúde.

No entanto, identificar a falta do planejamento, por si só, não é suficiente para compreender as razóes do 'não planejamento' da força de trabalho, haja vista a consciência da sua necessidade e importância indicadas, desde o início da construção do SUS, em diversos documentos oficiais.

A pesquisa bibliográfica realizada contribui para compreender que, além do conhecimento técnico, o 
processo de planejamento da FTS, ou a possibilidade de planejá-la, de acordo com as necessidades e os direitos sociais, está condicionado, entre outros fatores, ao modelo vigente de atenção à saúde, à resistência ou ao apoio de determinados sujeitos e grupos de interesses relacionados ao tema, que conseguem fazer prevalecer suas concepções sobre quais necessidades serão priorizadas, além de estar condicionado a determinantes sociais, políticos, econômicos e culturais, pois o número, o perfil e a distribuição de trabalhadores da saúde estão articulados a escolhas políticas e a valores e princípios a serem garantidos na organização dos sistemas de saúde.

Não fosse o planejamento da FTS (ou a ausência dele) um ato político, o que explicaria o fato de, no Brasil, a cobertura das equipes de saúde da família ser maior nas áreas onde há menos médicos disponíveis? No Nordeste brasileiro, as equipes de saúde da família cobrem $65 \%$ da população, apesar de esta região apresentar 1,01 médicos por mil habitantes, enquanto na região Sudeste, que apresenta a razão de 2,31 médicos por mil habitantes, a cobertura pelas equipes é de apenas 32\% da população.

Sem incorporar a dimensão política, de que outra maneira se pode explicar o fato de, apesar de a razão médicos/habitantes, no Brasil, ser o dobro da recomendada pela Organização Mundial de Saúde4, haver insuficiência de médicos para compor as equipes de saúde da família e de a cobertura da atenção básica ser ampliada, principalmente, em áreas onde essa razão é maior que a preconizada? Há médicos suficientes no Brasil, mas não no Sistema Único de Saúde e na atenção básica, especialmente.

Bahia $(2008,2009)$ enfatiza que não se trata apenas do montante de recursos públicos envolvido com a remuneração de prestadores privados, mas do reforço ao modelo assistencial oneroso, fragmentado, na maioria das vezes, e pouco efetivo, que tem excluído as concepções de universalização e necessidades de saúde do repertório das políticas de saúde. O rebaixamento do SUS à condição de comprador de serviços reduz o sistema de saúde ao consumo de procedimentos médico-hospitalares e a uma política pública de inclusão seletiva de demandas.
A racionalidade do processo de planejamento em saúde, no Brasil, historicamente, tem enfatizado os aspectos técnicos, e, mesmo estes, de maneira insuficiente, pois, inclusive os critérios 'técnicos', como eficiência, efetividade e equidade na alocação de recursos, têm sido desconsiderados em favor dos interesses econômicos e políticos do setor hegemônico na saúde, conforme denunciavam Castiel e Rivera (1985) já nos anos 1980.

É comum atribuir o fracasso do plano ao fracasso do método, e, com isso, buscar o aperfeiçoamento do método, intentando melhorar as possibilidades de alcançar os resultados desejáveis. No entanto, é necessário incorporar os sujeitos ao processo de planejamento e os aspectos políticos ao plano (SPINELLI; TESTA, 2005).

Considerar a indissociabilidade das dimensões técnica e política para o processo de planejamento e deste com a gestão impóe a reflexão sobre o contexto no qual o SUS tem-se constituído em um subsistema de saúde (o público), sem conseguir alcançar as prerrogativas constitucionais de universalidade de acesso e integralidade da atenção. Pelo contrário, de sistema único, ele tem-se colocado ao lado do subsistema privado e, em muitas situações, como complementar.

O passado recente, marcado pela submissão das politicas de formação de recursos humanos aos interesses empresariais-lucrativos [...], deixou como legado [...] a descoordenação e a multiplicidade de esforços, a inadequação do perfil da oferta e a má distribuição sociorregional dos recursos humanos. (BRASIL, 1993, p.191).

Apesar de ter sido realizada na década de 1980, pelo Grupo de Trabalho de Recursos Humanos da Comissão Nacional de Reforma Sanitária, essa análise permanece atual, e o contexto vinculado ao 'passado' ainda se mostra vigoroso. Esse arranjo público-privado tem sido apontado como um dos fatores centrais entre os obstáculos para a consolidação dos princípios doutrinários do SUS - fundamentalmente, a universalização, a integralidade e a igualdade no acesso aos serviços de saúde. 


\section{Referências}

ASSUNÇÃO, A.A. et al. Recursos humanos e trabalho em saúde: os desafios de uma agenda de pesquisa. Cadernos Saúde Pública, Rio de Janeiro, v. 23, n. 2, 2007. p. 193-201.

BAHIA, L. O sistema de saúde brasileiro entre normas e fatos: universalização mitigada e estratificação subsidiada. Ciência \& saúde coletiva, Rio de Janeiro, v. 14, n. 3, jun. 2009. p. 753-762.

As contradições entre o SUS universal e as transferências de recursos públicos para os planos e seguros privados de saúde. Ciência \& saúde coletiva, Rio de Janeiro, v. 13, n. 5, out. 2008. p. 1385-1397.

BOTTOMORE, T. Dicionário do pensamento marxista. Rio de Janeiro: Zahar, 1988.

BRASIL. Ministério da Saúde. A questão dos recursos humanos nas conferências nacionais de saúde - 1941-1992. Cadernos RH Saúde, Brasília, ano 1, v. 1, n. 1, 1993.

BRASIL. Ministério da Saúde. Conselho Nacional de Saúde. Princípios e diretrizes para a gestão do trabalho no SUS (NOB/RH-SUS). 3. ed. rev. atual. Brasília: Ministério da Saúde, 2005.

BRASIL. Ministério da Saúde. Secretaria de Gestão do Trabalho e da Educação na Saúde. Organização Pan-Americana da Saúde. Reunião regional dos observatórios de recursos humanos em saúde. Chamado à ação de Toronto: 2006-2015 rumo a uma década de recursos humanos em saúde nas Américas. Brasília: Ministério da Saúde, 2006a.

BRASIL. Ministério da Saúde. Secretaria de Gestão do Trabalho e da Educação na Saúde. Departamento de Gestão e da Regulação do Trabalho em Saúde. Programa Nacional de Desprecarização do Trabalho no SUS: DesprecarizaSUS - perguntas e respostas, Brasília: Ministério da Saúde, 2006b.

BRASIL. Ministério da Saúde. Portaria n. 3.085, de 1 de dezembro de 2006. Regulamenta o Sistema de Planejamento do SUS. Saúde Legis: Sistema de Legislação da Saúde, 2006c. Disponível em: <http://bvsms.saude.gov.br/bvs/saudelegis/gm/2006/ prt3085_01_12_2006.html>. Acesso em: 26 jan. 2012.

Portaria n. 1.318, de 5 de junho de 2007. Diretrizes Nacionais para a Instituição ou Reformulação de Planos de Carreiras, Cargos e Salários, a título de subsídios técnicos à instituição de regime jurídico de pessoal no âmbito do Sistema Único de Saúde, que se recomendam a seus gestores, respeitada a legislação de cada ente da Federação. Saúde Legis: Sistema de
Legislação da Saúde, 2007. Disponível em: <http://bvsms.saude. gov.br/bvs/saudelegis/gm/2007/prt1318_05_06_2007.html>. Acesso em: 30 jan. 2012.

BRASIL. Ministério da Saúde. Sítio da Secretaria de Gestão do Trabalho e da Educação na Saúde SGTES na web. Portal da Saúde - SUS. Disponível em: <http://portal.saude.gov.br/portal/saude/ Gestor/area.cfm?id_area=382>. Acesso em 20 jun. 2011.

BREILH, J. Epidemiologia crítica: ciência emancipadora e interculturalidade. Rio de Janeiro: Fiocruz, 2006.

CASTIEL, L.D.; RIVERA, F.J.U. Planejamento em Saúde e Epidemiologia no Brasil: casamento ou divórcio? Caderno de Saúde Pública, Rio de Janeiro, v. 1, n. 4, dez. 1985. p. 447-456.

HALL, T.L.; MEJÍA, A. Planificación del personal de salud: principios, métodos, problemas. Genebra: OMS, 1978.

LUZ, M. T. Notas sobre as políticas de saúde no Brasil de 'transição democrática' - anos 80. Physis, Rio de Janeiro, v. 1, n. 1, 1991. p.7795.

MACHADO, M.H. Trabalhadores da saúde e sua trajetória na reforma sanitária. In: BRASIL. Ministério da Saúde. Secretaria de Gestão do Trabalho e da Educação na Saúde. Cadernos RH Saúde, Brasília, v.3, n. 1,2006.

MACHADO, C.V.; BAPTISTA, T.W.F.; NOGUEIRA, C.O. Políticas de saúde no Brasil nos anos 2000: a agenda federal de prioridades. Cadernos Saúde Pública, Rio de Janeiro, v. 27, n. 3, mar. 2011. p. 521-532.

MEDEIROS, C.R.G. et al. A rotatividade de enfermeiros e médicos: um impasse na implementação da Estratégia de Saúde da Família. Ciência \& saúde coletiva, Rio de Janeiro, v. 15, supl.1, 2010.

MOTA, A. E. Crise contemporânea e as transformações na produção capitalista In: Serviço social: direitos sociais e competências profissionais, Brasília, DF: CFESS/ABEPSS, 2009.

NORONHA, J.C.; SOARES, L.T. A política de saúde no Brasil nos anos 90. Ciência \& saúde coletiva, Rio de Janeiro, v.6, n.2, 2001, p. 445-450.

ONOCKO-CAMPOS, R. Planejamento e razão instrumental: uma análise da produção teórica sobre planejamento estratégico em saúde, nos anos noventa, no Brasil. Cadernos Saúde Pública, Rio de Janeiro, v.16, n.3, set. 2000, p.723-731. 
OPAS - ORGANIZAÇÃO PAN-AMERICANA DE SAÚDE. PPREPSPrograma de Preparação Estratégica de Pessoal de Saúde - OPASBrasil. Brasília: OPAS-Brasil. 1976. Disponível em: <http://www. coc.fiocruz.br/observatoriohistoria/opas/producao/arquivos/ PPREPS.pdf.>. Acesso em: 24 maio 2011.

OPAS - ORGANIZAÇÃO PAN-AMERICANA DE SAÚDE. Conferencia Panamericana sobre Planificación de Recursos Humanos en Salud, Ottawa/Canadá, 10-14 de setembro de 1973. Washington: OPAS, 1974. $134 \mathrm{p}$.

PAIM, J.S.; TEIXEIRA, C.F. Política, planejamento e gestão em saúde: balanço do estado da arte. Revista Saúde Pública, São Paulo, v. 40, ago 2006. p.73-78. Suplemento.

PEREIRA, L.D. A gestão da força de trabalho em saúde na década de 90. Physis, Rio de Janeiro, v. 14, n. 2, 2004. p. 363-382.

PIRES-ALVES, F.A.; PAIVA, C.H.A. Recursos críticos: história da cooperação técnica Opas-Brasil em recursos humanos para a saúde (1975-2008). Rio de Janeiro: Fiocruz, 2006.

QUINTANA, P.E.B.; RÍGOLI, F.; PADILHA, M. Planificación de recursos humanos y reformas del sector salud. In: NEGRI, B.; FARIA, R.; VIANA, A.L.D. (Org.) Recursos humanos em saúde: política, desenvolvimento e mercado de trabalho. São Paulo: Unicamp - NEPP, 2002, p.189-220.
ROMERO, L.C. O debate entre planejamento de recursos humanos para a saúde e autonomia universitária no parlamento brasileiro. Revista Direito Sanitário, São Paulo, v. 9, n. 3, nov. 2008. p. 75-88.

ROVERE, M.R. Planificación estratégica de recursos humanos en salud. 2. ed. Washington: OPAS-OMS, 2006.

SILVEIRA, D.S. et al. Gestão do trabalho, da educação, da informação e comunicação na atenção básica à saúde de municípios das regiões Sul e Nordeste do Brasil. Cadernos Saúde Pública, São Paulo, v. 26, n. 9, set. 2010. p. 1714-1726.

SPINELLI, H.; TESTA, M. Del Diagrama de Venn al Nudo Borromeo: recorrido de la planificación en América Latina. Salud Colectiva, Lanús, v. 1, n. 3, dez. 2005. p.323-335.

TOLEDO, C. N. O Governo Goulart e o golpe de 64. 4 ed. São Paulo: Brasiliense, 1984 (Coleção Tudo é História).

VARELLA, T.C.; PIERANTONI, C.R. Mercado de trabalho: revendo conceitos e aproximando o campo da saúde. A década de $90 \mathrm{em}$ destaque. Physis, Rio de Janeiro, v. 18, n. 3, 2008, p. 521-544.

Recebido para publicação em julho de 2013

Versão definitiva em dezembro de 2013

Suporte financeiro: não houve

Conflito de interesse: inexistente 